\title{
Investigation of Recombinant Tissue Plasminogen Activator Complications in Treatment of patients with ischemic stroke visiting Vali-e-Asr hospital in Birjand, 2016-2017
}

\section{Hamid Reza Riasi}

birjand university of medical science

Elham Zarei

birjand university of medical science

Forod Salehi ( $\sim$ hamidsalehi500@yahoo.com )

Fatemeh Sayehmiri

Shahid Beheshti University of Medical Sciences School of Traditional Medicine

\section{Research article}

Keywords: Clinical Trial, Brain Ischemia, Stroke, Dual Antiplatelet Therapy, Tissue Plasminogen Activator, Complication, Treatment

Posted Date: August 14th, 2019

DOI: https://doi.org/10.21203/rs.2.12855/v1

License: (c) (i) This work is licensed under a Creative Commons Attribution 4.0 International License.

Read Full License 


\section{Abstract}

Background: Current treatment options for the sake of treating acute ischemic stroke include recombinant tissue plasminogen activator or dual anti platelet therapies. This study aims to evaluate the complications of recombinant tissue plasminogen activator in treatment of patients with ischemic stroke who were admitted in Vali-e-Asr hospital in Birjand, 2016-2017. Method: This descriptive analytic study was performed on patients with acute ischemic stroke who were admitted in neurology ward of Vali-e-Asr hospital in Birjand from 2016 to 2017. A total of 127 patients participated in this study. The data about complications of treatment were collected by questionnaires and entered into SPSS 21 . Then, data were analyzed by Chi-square or Fisher exact test at a significant level of $p \leq 0.5$. Results: A total of 127 subjects received treatment for ischemic stroke. Thirty-one (24.4\%) patients have been treated with recombinant tissue plasminogen activator and ninety-six $(75.6 \%)$ have been treated conventionally with dual antiplatelet. These two groups were matched in terms of age and sex. The history of hypertension in the recombinant tissue plasminogen activator group and the conventional treatments were $32.3 \%$ and $67.7 \%$, respectively $(p=0.03) .99 \%$ of patients in the antiplatelet treatment group $(\mathrm{N}=96)$ and $96.8 \%$ of patients in the recombinant tissue plasminogen activator group $(\mathrm{N}=31)$ have been discharged and one death was occurred in each group $(p=0.4)$. Regarding the incidence of recombinant tissue plasminogen activator complications, IVH was reported in two patients $(6.5 \%, \mathrm{p}=0.06)$ Conclusion: The incidence of mortality was the same in two groups. Also, complications were only reported in two patients in the recombinant tissue plasminogen activator group (both intraventricular hemorrhage) and the difference was not statistically significant. Researchers recommend that more clinical trials must be conducted. If it is approved, the findings of the current studies will be widely taken into consideration for acute stroke treatment.

\section{Background}

Acute neurologic deficit occurred after sudden occlusion of brain blood flow. Stroke incidence in United States is about 800.000 each year which most cases are ischemic (almost $90 \%$ ). Stroke is the fifth cause of death in adults and the resulting disability accounts for over $\$ 72$ billion in healthcare costs (1). The cost is predicted to be triple from 2012 to 2030 , as the general population ages and reaches $\$ 184$ billion (2). Stroke classification system has been defined based on a multi-center clinical trial of ORG (10172 in Acute Stroke Treatment) 10172 in TOAST. The main subtypes of ischemic CVA are 1) Large-artery, 2) Small-vessel or lacunar and 3) Cardioembolic infarction.

Most stroke treatments options are based on Recanalization strategies carried out by intravenous injection of recombinant tissue plasminogen activator (rt-PA) or intra-arterial approaches. The goal of these strategies is the reconnection of blood flow of ischemic region so that penumbra cells (an active metabolic part located around the ischemic region which its cells are potentially lifesaving) will be saved before the occurrence of irreversible damage (4). Of course, the effectiveness of these treatments is to prescribe them in the least possible time (5). 
In 2009, the American Food and Drug Administration (FDA) approved the use of rt-PA in ischemic stroke treatment (if there are criteria introduced by the National Institute of Neurological Disorders and Stroke [NINDS]) (6). This drug should be prescribed in particular by CT scan during the first 3 hours of stroke symptom onset (7). Of course, today, due to the clinical trial data of European Cooperative Acute Stroke Study III (ECASS III), longer period of time (up to 4.5 hours after the symptom onset) in most institutes (and also from the American heart association [AHA/ ASA]) is accepted (8). This issue defined that more patients benefit from this treatment $(9,10)$. In a meta-analysis carried out on 9 main clinical trials and on 6756 patients with acute ischemic stroke undergoing fibrinolysis treatment, researchers showed that alteplase injection during 4.5 hours of symptoms onset is associated with a significant improvement outcome, regardless of age and stroke severity.

Different studies have reportedly mentioned scattered complications for rt-PA and no comprehensive study has been done yet to examine the complications of this drug in an appropriate sample size of patients. This study was conducted to investigate the rt-PA complications in treating ischemic stroke patients who were admitted in Vali-e-Asr hospital in Birjand, 2016-2017.

\section{Methods}

This cross sectional study was performed on all patients affected by acute ischemic stroke who were admitted in neurology ward in Vali-e-Asr hospital in Birjand, 2016-2017. The proposal protocol was approved by the ethics committee of Birjand university of medical sciences (BUMS) with the code number of: Ir.bums.REC.1395.172 and was registered in Iran's Clinical Trial Registration Center on Jun 10, 2017, coded IRCT2017082117756N24.

Entry criteria for rt-PA group, included symptom onset less than 4.5 hours, absence of cerebral hemorrhage on CT scan and NIHSS clinical score more than 4 and less than 18 . The prescribed contraindications of rt-PA included ages more than 80 , evidence of hemorrhagic stroke in imaging, NIHSS clinical score more than 25, patients treated with anticoagulants, patients with evidence of major stroke or involvement of more than one-third of the MCA in CT scans. Patients who do not meet eligibility criteria for treatment with rt-PA, based on the entry and exit criteria, were treated by antiplatelet therapy.

Treatment in rt-PA group was carried out at a dose of $0.9 \mathrm{mg} / \mathrm{kg}$ (the maximum dose of $90 \mathrm{mg}$ ), $10 \%$ of calculated dose, as the initial dose and the remaining $90 \%$ of that were infused during 60 minutes. Antiplatelet treatment was conducted as dual anti platelet therapy using Aspirin and Clopidogrel. Therefore, Aspirin $(80 \mathrm{mg})$ and Clopidogrel $(75 \mathrm{mg})$ were daily used by patients for up to 3 months and after that the Clopidogrel discontinued, but aspirin therapy continued.

QForty eight hours of intensive care and careful examination of bleeding in all organs were performed. After the completion of treatment and patient discharge, all related information, events and clinical status of the patient were recorded and controlled. The rate of treatment complications was examined based on the patient's symptoms and imaging methods and were compared in terms of age and sex. The collected data were entered into the SPSS 21. Data description was done using descriptive statistics (mean, SD 
and percentage distribution). Chi square test and Fisher's exact test were used at a significant level of $P \geq 0.5$ to analyze data.

\section{Results}

During this study, a total of 127 subjects were treated due to the ischemic stroke that among them, 31 (24\%) and 96 (75.6\%) patients were treated by rt-PA and by conventional antiplatelet treatments, respectively. Two aforementioned groups were matched in terms of age and gender (Table1). The findings of this study displayed that there was a significant difference between two groups regarding the stroke risk factors, so that those undergoing conventional antiplatelet treatments had more risk factors $(82.3 \%, 61.3 \%$ and $p v=0.03$, respectively). Table -1 shows comparison risk factors in two groups.

CT scan results of patients in two groups revealed that there was no significant difference between two groups ( $\mathrm{pv}=0.09$ and $\mathrm{Phi}=0.24)$.

Regarding the complications in two groups, intraventricular hemorrhage (IVH) was reported only in two patients of rt-PA group $(6.5 \%, \mathrm{pv}=0.06)$. Final results of patients at discharge showed that $99 \%$ of patients in antiplatelet group and $96.8 \%$ of patients in rt-PA group were discharged and one case of death was reported in each group $(p v=0.06)($ Table-2).

\section{Discussion}

This analytical descriptive study, searched the rt-PA complications in treatment of ischemic stroke patients who were admited in Vali-e-Asr hospital in Birjand between 2016-2017. Results of this study showed that the only complication observed in rt-PA group was cerebral hemorrhage. No other complication was seen in patients under the treatment in this study. No complication was observed in patients of antiplatelet group. Mortality was the same in two groups. It is worth noting that rt-PA dose in this study was $0.9 \mathrm{mg} / \mathrm{Kg}$ (maximally $90 \mathrm{mg}$ ), ten percent of calculated dose was administered as bolus and the rest was infused within an hour. In our study there was no complications with antiplatelet dual therapy.

Other studies carried out in this regard showed relatively few complications of antiplatelet dual therapy in patients with acute stroke $(12,13)$. However, the results of this study showed that the increased risk of bleeding in patients undergoing long term treatment with Clopidogrel is one of the main issues in antiplatelet therapy (14).

Overall, the results of different studies showed, increased risk of intracranial hemorrhage. Based on the studies, the careful and conservative selection of patients is aligned with hemorrhage reduction (at the cost of depriving a part of patients from rt-PA treatment). In a double blind clinical trial with the placebo control by Hacke and colleagues, thrombolysis was carried out within 3 to 4.5 hours after stroke using alteplase. This study confirmed intracranial hemorrhage was significantly more reported in patients 
undergoing treatment with alteplase than in the placebo group. Although they have often been asymptomatic and non-lethal.

Other complications and also the mortality rate between two groups were the same (8). In the double blind clinical trial carried out by the IST-3 collaborative group, patients were randomized to receive rt-PA or placebo. Totally, the results of the study showed that, contrary to the results of the present paper, the risk of intracranial and extra-cranial hemorrhage significantly increased with rt-PA prescription. However, no difference was seen in other complications (15). Along with the results of this research, one study by Tekle et.al. on the treatment outcomes of patients with stroke in different time intervals indicated that the frequency of mortality in rt-PA group during the first three hours was comparable to that in patients undergoing thrombectomy during the first 2.5 to 4 hours (16). Finally, in consistency with the results of the present paper on performed meta-analysis by Wardlaw et al. on 12 studies with sample size of 7012 patients after collecting the overall results of clinical trial mortality showed complications including lethal intracranial hemorrhage $(\mathrm{ICH})$, symptomatic $\mathrm{ICH}$ and brain edema revealed no any meaningful mortality difference in rt-PA group in comparing with control group.

Considering the results of previous studies which confirm the safety of rt-PA treatment, with correct choice of patients, the use of this therapeutic approach can be highly recommended.

Another finding of this study was the higher frequency of stroke risk factors in patients who have received only antiplatelet treatment (particularly hypertension). Despite the fact that the blood pressure level was not one of the entry or exit criteria for entering the rt-PA treatment group, the use of this therapy for this group of patients was always disputed. Studies carried out before the drug approval by FDA showed that systolic blood pressure over $185 \mathrm{mmHg}$ and diastolic blood pressure greater than $110 \mathrm{mmHg}$ were associated with an increased risk of symptomatic intracerebral hemorrhage (17). The data from the subsequent studies also accentuated the actual and definite increased risk of symptomatic ICH associated with hypertension (18). Based on a sub analysis of the data on study, it was revealed that high systolic blood pressure was associated with hemorrhagic transformation after rt-PA therapy, which implies that high blood pressure might not be the only cause of symptomatic ICH; however, high blood pressure itself was due to the occurrence of hemorrhage in rt-PA prescription. This probable theory was approved by observing hematoma expansion in the area of high blood pressure created as a result of rtPA (20).

By comparing patients with placebo and rt-PA, analysis of ECASS-II study data showed that favorable outcome has reverse relationship with the basic systolic blood pressure, the maximum and average of blood pressure over a 24-hour period and also changes in blood pressure level. In a retrospective analysis of SITS-ISTR database, the results indicated that there was a U- shape relationship between blood pressure and the occurrence of symptomatic intracranial hemorrhage and the best results have been observed with $140 \mathrm{mmHg}$ systolic blood pressure. Despite these findings, there is no consensus on intravenous aggressive treatment of high blood pressure in patients with ischemic stroke (to start rt-PA). However, it seems that a group of patients undergoing antiplatelet drug treatment in this study were 
deprived of rt-PA treatment due to hypertension that this issue happened regardless of the design criteria (based on the physician's mindset and clinical decision making).

\section{Conclusion}

In this study, the occurrence of mortality was the same between the two groups, against two complicated cases in rt-PA case (both IVH). There was no significant difference between two groups according to mortality and complications however, small sample size of patients who received rt-PA treatment limits generalization of this study, but by respect the result of previous studies which confirms treatment safety with rt-PA (with correct choice of patients), rt-PA approach can be recommended after meticulous clinical trials. As already mentioned, one of the limitation of this study is small sample size. Against the fact that complications of this treatment approach are rare, it is wiseful to examine higher number of patients to find out incidence of complications, and recommendation in more patients in future studies. Considering conservative approach in dealing with hypertension history, it is advisable to register blood pressure profile of patients.

\section{Abbreviations}

\section{$R t-P A:$ recombinant tissue plasminogen activator}

\section{NINDS: National Institute of Neurological Disorders and Stroke}

\section{AHA: American heart association}

\section{ECASS III: European Cooperative Acute Stroke Study III}

\section{IVH: intraventricular hemorrhage}

\section{Declarations}

\section{Conflict of Interest statement:}

No conflict

\section{Ethics approve:}

The proposal protocol was approved by the ethics committee of Birjand University of medical sciences (BUMS) with the code number of: Ir.bums.REC.1395.172 


\section{Consent for publication:}

Not Applicable

\section{Authors Contributions:}

HRR and EZ designed the conception of the study; FAS focus of the statically analysis; FOS, technical support and conceptual advice. All authors contributed to the drafted the manuscript, revised it critically and approved the final version.

\section{Funding:}

No funding was obtained for this study

\section{Competing Interests:}

No Competing Interests

\section{Availability of data and materials:}

Not applicable

\section{Acknowledgements:}

The authors extend their gratitude to the Atherosclerosis and Coronary Artery Research Center, Birjand University of Medical Sciences.

\section{References}

1. Mandelzweig L, Goldbourt U, Boyko V, Tanne D. Perceptual, Social, and Behavioral Factors Associated With Delays in Seeking Medical Care in Patients With Symptoms of Acute Stroke. Stroke. 2006; 37(5):1248-53.

2. Ovbiagele B, Goldstein LB, Higashida RT, Howard VJ, Johnston SC, Khavjou OA, et al. Forecasting the Future of Stroke in the United States. A Policy Statement from the American Heart Association and American Stroke Association. 2013; 44(8):2361-75.

3. Sacco RL, Shi T, Zamanillo MC, Kargman DE. Predictors of mortality and recurrence after hospitalized cerebral infarction in an urban community: the Northern Manhattan Stroke Study. Neurology. 1994; 44(4):626-34. 
4. Mergenthaler P, Dirnagl U, Meisel A. Pathophysiology of stroke: lessons from animal models. Metabolic brain disease. 2004; 19(3-4):151-67.

5. Goyal M, Jadhav AP, Bonafe A, Diener H, Pereira V, Levy E, et al. Good Outcome After Successful Recanalization is Time Dependent in the Swift Prime Randomized Controlled Trial. Am Heart Assoc; 2016.

6. Zivin JA. Acute stroke therapy with tissue plasminogen activator (tPA) since it was approved by the US Food and Drug Administration (FDA). Annals of neurology. 2009; 66(1):6-10.

7. Frankel MR, Morgenstern L, Kwiatkowski T, Lu M, Tilley B, Broderick J, et al. Predicting prognosis after stroke A placebo group analysis from the National Institute of Neurological Disorders and Stroke rt-PA Stroke Trial. Neurology. 2000; 55(7):952-9.

8. Hacke W, Kaste M, Bluhmki E, Brozman M, Dávalos A, Guidetti D, et al. Thrombolysis with Alteplase 3 to 4.5 Hours after Acute Ischemic Stroke. New England Journal of Medicine. 2008; 359(13):1317-29.

9. Wahlgren N, Ahmed N, Dávalos A, Hacke W, Millán M, Muir K, et al. Thrombolysis with alteplase 3\&\#x2013;4\&\#xb7;5 h after acuteischaemic stroke (SITS-ISTR): an observational study. The Lancet. 2008; 372(9646):1303-9.

10. Jauch EC, Saver JL, Adams HP, Bruno A, Connors JJ, Demaerschalk BM, et al. Guidelines for the Early Management of Patients with Acute Ischemic Stroke. A Guideline for Healthcare Professionals from the American Heart Association/American Stroke Association. 2013; 44(3):870-947.

11. Emberson J, Lees KR, Lyden P, Blackwell L, Albers G, Bluhmki E, et al. Effect of treatment delay, age, and stroke severity on the effects of intravenous thrombolysis with alteplase for acute ischaemic stroke: a meta-analysis of individual patient data from randomised trials. The Lancet. 2014; 384(9958):1929-35.

12. .Hong K-S. Dual Antiplatelet Therapy after Noncardioembolic Ischemic Strokeor Transient Ischemic Attack: Pros and Cons. Journal of Clinical Neurology (Seoul, Korea). 2014; 10(3):189-96.

13. Asdaghi N, Romano JG. Dual antiplatelet therapy in acute ischemic stroke. Current atherosclerosis reports. 2015; 17(7):37.

14. Berger PB, Bhatt DL, Fuster V, Steg PG, Fox KAA, Shao M, et al. Bleeding Complications With Dual Antiplatelet Therapy Among Patients With Stable Vascular Disease or Risk Factors for Vascular Disease. Results from the Clopidogrel for High Atherothrombotic Risk and Ischemic Stabilization, Management, and Avoidance (CHARISMA) Trial. 2010; 121(23):2575-83.

15. The IST-3 collaborative group. The benefits and harms of intravenous thrombolysis with recombinant tissue plasminogen activator within $6 \mathrm{~h}$ of acute ischaemic stroke (the third international stroke trial [IST-3]): a randomised controlled trial. Lancet. 2012; 379(9834):2352-63.

16. Tekle WG, Chaudhry SA, Fatima Z, Ahmed M, Khalil S, Hassan AE, et al. Intravenous Thrombolysis in Expanded Time Window (3-4.5 hours) in General Practice with Concurrent Availability of Endovascular Treatment. Journal of vascular and interventional neurology. 2012; 5(1):22-6.

17. Wardlaw JM, Murray V, Berge E, del Zoppo G, Sandercock P, Lindley RL, et al. Recombinant tissue plasminogen activatorfor acute ischaemic stroke: an updated systematic review and meta-analysis. 
Lancet. 2012; 379(9834):2364-72.

18. Perini F, De Boni A, Marcon M, Bolgan I, Pellizzari M, Dionisio LD. Systolic blood pressure contributes to intracerebral haemorrhage after thrombolysis for ischemic stroke. Journal of the Neurological Sciences. 2010; 297(1):52-4.

19. Butcher K, Christensen S, Parsons M, De Silva DA, Ebinger M, Levi C, et al. Postthrombolysis Blood Pressure Elevation Is Associated With Hemorrhagic Transformation. Stroke. 2010; 41(1):72-7.

20. Mokin M, Kass-Hout T, Kass-Hout O, Zivadinov R, Mehta B. Blood pressure management and evolution of thrombolysis-associated intracerebral hemorrhage in acute ischemic stroke. Journal of stroke and cerebrovascular diseases: the official journal of National Stroke Association. 2012; 21(8):852-9.

21. Yong M, Kaste M. Association of Characteristics of Blood Pressure Profiles and Stroke Outcomes in the ECASS-II Trial. Stroke. 2008; 39(2):366-72.

22. Ahmed N, Wahlgren N, Brainin M, Castillo J, Ford GA, Kaste M, et al. Relationship of Blood Pressure, Antihypertensive Therapy, and Outcome in Ischemic Stroke Treated With Intravenous Thrombolysis. Retrospective Analysis from Safe Implementation of Thrombolysis in Stroke-International Stroke Thrombolysis Register (SITS-ISTR). 2009; 40(7):2442-9.

\section{Tables}

Table 1: Demographic information and ischemic stroke risk factors in patients of rt-PA and antiplatelet groups 


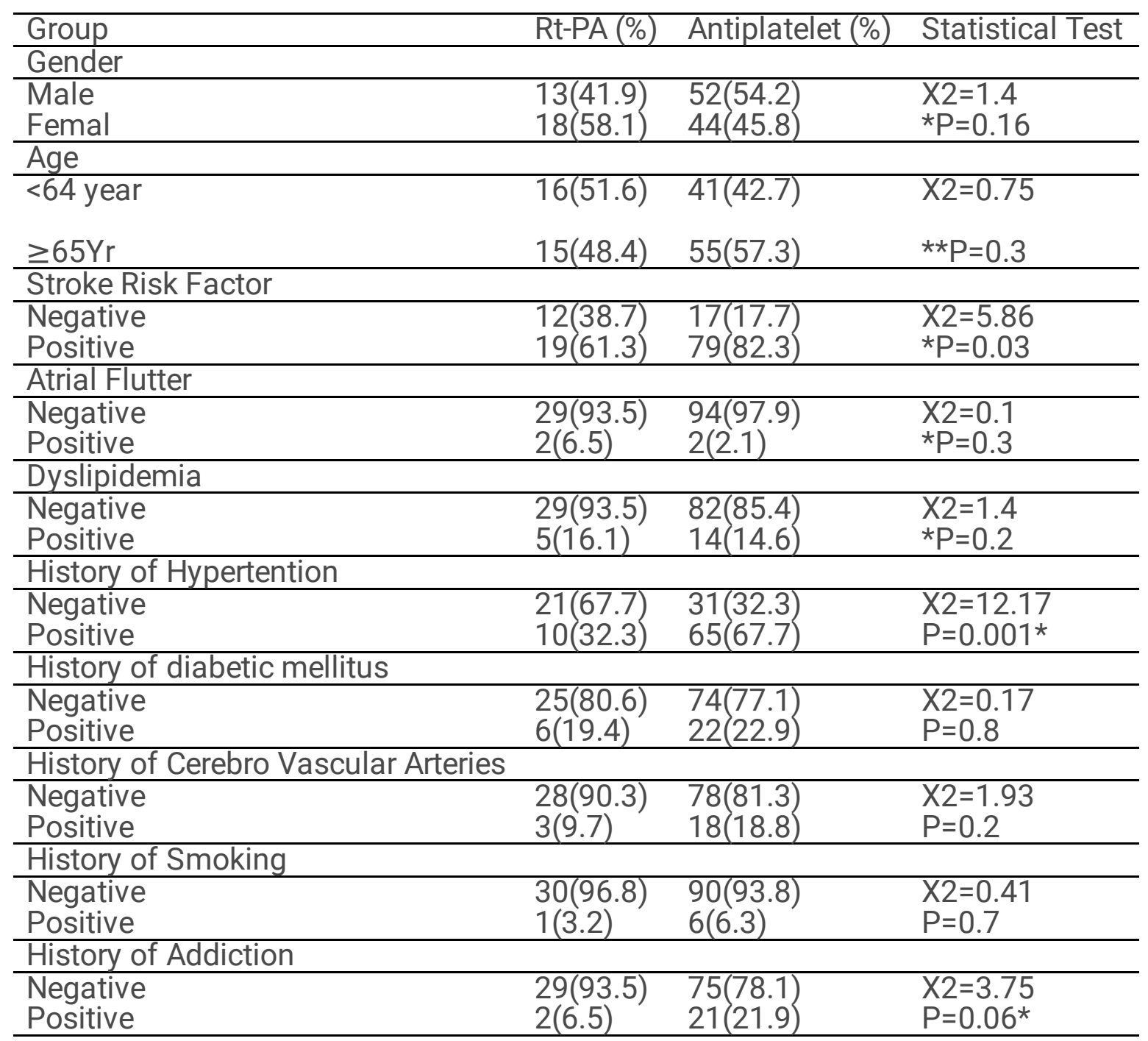

Table 2: Comparison of complications during the treatment in the two groups of investigation

\begin{tabular}{llll}
\hline & rt-PA & Conventional treatment(96) & Statistical test \\
& $(31)$ & & \\
\hline Results & & & \\
\hline Discharge & $30(96.8)$ & $95(99)$ & $0.07=\mathbf{X}^{2}$ \\
Expire & $1(3.2)$ & $1(1)$ & $0.4^{*}=\mathrm{p}$ \\
\hline Complications & & & $0.2=\mathbf{X}^{2}$ \\
\hline Negative & $29(93.5)$ & $96(100)$ & ${ }^{*} 0.06=\mathrm{p}$ \\
Positive & $2(6.5)$ & $0(0)$ & \\
\hline
\end{tabular}

* The result of fisher's exact test was not significant.

** Both of the complications are observed IVH. 


\section{Supplementary Files}

This is a list of supplementary files associated with this preprint. Click to download.

- CONSORT2010FlowDiagram.pdf 